\title{
Oscillatory neuronal dynamics during language comprehension
}

\author{
Marcel Bastiaansen* and Peter Hagoort
}

FC Donders Centre for Cognitive Neuroimaging, Radboud University, PO Bax 9101,6500 HB Nijmegen, The Netherlands

\begin{abstract}
Language comprehension involves two basic operations: the retrieval of lexical information (such as phonologic, syntactic, and semantic information) from long-term memory, and the unification of this information into a coherent representation of the overall utterance. Neuroimaging studies using hemodynamic measures such as PET and fMRI have provided detailed information on which areas of the brain are involved in these language-related memory and unification operations. However, much less is known about the dynamics of the brain's language network. This chapter presents a literature review of the oscillatory neuronal dynamics of EEG and MEG data that can be observed during language comprehension tasks. From a detailed review of this (rapidly growing) literature the following picture emerges: memory retrieval operations are mostly accompanied by increased neuronal synchronization in the theta frequency range $(4-7 \mathrm{~Hz})$. Unification operations, in contrast. induce high-frequency neuronal synchronization in the beta $(12-30 \mathrm{~Hz}$ ) and gamma (above $30 \mathrm{~Hz}$ ) frequency bands. A desynchronization in the (upper) alpha frequency band is found for those studies that use secondary tasks, and seems to correspond with attentional processes, and with the behavioral consequences of the language comprehension process. We conclude that it is possible to capture the dynamics of the brain's language network by a careful analysis of the event-related changes in power and coherence of EEG and MEG data in a wide range of frequencies, in combination with subtle experimental manipulations in a range of language comprehension tasks. It appears then that neuronal synchrony is a mechanism by which the brain integrates the different types of information about language (such as phonological, orthographic, semantic, and syntactic information) represented in different brain areas.
\end{abstract}

Keywords: language comprehension; unification; syntax; semantics; neuronal synchronization; oscillatory dynamics; EEG power; EEG coherence

\section{Introduction}

Understanding natural language or, roughly stated, the mapping of sound or orthography onto meaning, is a deceivingly simple task for most of us. The fact that language comprehension is a hard-to-suppress "reflex" is nicely illustrated, for

*Corresponding author.

E-mail: marcel.bastiaansento fcdonders.ru.n] instance, by the word interference effect in a standard color-word Stroop task (e.g., MacLeod, 1991). Yet, understanding how language comprehension is achieved is by all means a much more difficult enterprise. Indeed, studying language comprehension (and other aspects of language processing, such as language production, language acquisition, and more generally the relation between language, thought, and culture) has evolved into a large and active research field, that of psycholinguistics. 
Traditionally, psycholinguistic research has mide use of empirical methods such as behavioral experiments. computational modeling, the analysis of cross-linguistic differences. and many more. However, a seminal paper by Kutas and Hillyard (1980) showed that some aspects of semantic processing induce reliable responses in the EEG recordings of normal. healthy subjects. Since then, connitive neuroscientific methods have become increasingly popular in psycholinguistic rescarch (sec, c.l.. Brown and Hagoort. 1999). The suecess. ir pispulatrity of the cognilive neuroscience of lantaitec lallhough buing stimulated by the emerternec of new hrain imaging lechnicutes like PET. IMRI. and MECi). is forr a large part based on the

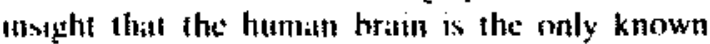
ystem thal is at ble to fluenty produce and ander-

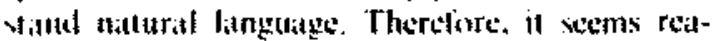
volitble to assume that at better understanding of the neutenal processes anderlyirg language comprehensw will to helplul in shaping the existing functional models af language comprehension

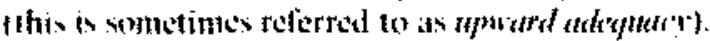
Vice tersis. the same functionat wodeds may be hesplut in suiding our anderstanding of the neurunil presesses that are observed during langualge cumprehension (downward atequacy).

In this chapter we concentrate on the rapid dantmicis of the neurat processes anderlying langriage comprehension. However. hefore turning to this. let us tirst brielly deltneate at a bery generat les af what is thought to be the esgnitise architedture af linguage somprehension.

It is goneratly atgred that during languatex comprehansion. tncoming sounds or orthographic palterns trigger al calsciate of memory retriesal

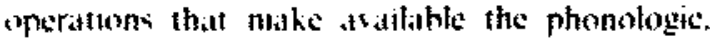
Yntactic, athal semantic properties of indivialuat warth Onts at allithe. these different ingredient:

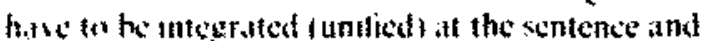

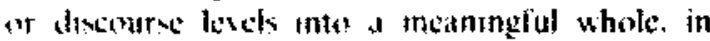
"uder to veld a coherent interpretallon of the lin. gulstic mput lee Hageort. 200 s far a more actalca claboration of this framework. Thus. two different ognitive processes, namely memory retricsal operations and unification operations. play a srukial role during language comprehension.
Note that in this formulation it is a very general framework that does not address most of the more detailed -- and often hotly debated . . issues in language comprehension research (e.g., whether or not syntactic analysis precedes semantic analysis, compare. e.g., Marslen-Wilson and Tyler, 1980 and Friederici, 2002). However, exactly by avoiding such details it provides a common ground for most psycholinguistic researchers - and a good starting point for entering the avalable neural duta into the debate.

\section{The brain's language networks structure}

Fver since Paul Broca and Carl Wernicke joente lied separate areas in the brain that are specialized for certain atspects of language pricessing, it hat been evident that there must be a distributed network in the brain that is responsible for language processing. Hemodynamic neuroimaging lechniques such as PFT and fMRI. with their excellent spatial resolution. are particularly suited for identifying the different brain areats that participate in this distributed network. or stated differently. to unveil the structure of the hrain's languatge network.

Although language is a very well-delineated cognitive function. the neural structures involved in the memory operations involved in retrieving stored linguistic knowledge are likely to have evolved from, and therefore at least show a good deal of everlap with. the structures involved in retricsing domain-general knowledge. A large number of hemodynamic studies have linked the (domain-general) retrieval of declarative ri.e. factual and episodic) information from long-term memory fo inereased blood oxygenation level dependent (BOLD) activity in a large number of areas including prefrontal. temporal. anterkor cingulate. and cerehellar arcats tsee Cabeza and Nyberg. 2000 for a rexiew). The medial temporal lobe (MTL) system is assumed 10 play a central role in memory operations. in that if establishes cortico-hinpocampal kops that serve the purpose of coactivating distributed cortical areas in which the relevant information is stored fe.g. Miller. 1991: Murre et al. 2001). Among the cortical areas that have been specifically associated with retricsal 
of lexital information in the context of language comprehension are the central and posterior parts of the left middle and superior temporal gyri. and the posterior inferior frontal gyrus (see Wise, 2003; Indefrey. 2004: Indefrey and Cutler, 2005 for reviews and metid-analyses).

Linguistic unification operations pertaining to the domatins of phonology. syntax. and semantics are thought to be carried out in it set of brain regions including the left inferior frontal gyrus I Brocia $\mathrm{s}$ atea and surrounding tissue, roughly $B A$ s 4. 45, 47, and ventral BA 6, see Hagcort, 2005 for aletetls, itted possibly the left posilerior superior kemperal gyrus (Indefrey and Cutler. 2005). In the leti infiertur lrontlat gyrus, there appears to the reyowal specilicity for phomology. syntax, and somitntas tace the revew by Bookheimer. 2002).

\section{The brain's language nerwork: what abowt the dynamiss."}

The hret literat ure wertiew presented abowe show That the network of britin strustures that contributes wi the precess of languiles comprehension is beaming increasifyll well tunderstowl. Howeser. duc wo the inherently poor temporal resolution of hemody namie measures (i.c. in the order of seconds). the resulting picture is a rather static one. emphasizing mainls the structural aspects of the brain s languige metwork. This static view roes not do justice to the ds namic properties that ans langaige comprehenvon darice mest hatse. Normal speech has a rate of shou three to tive words per second. which means that the linguistic retrieval and unification operatwons must be tarried aut wers rapidls. Therefore. tring fo understand the neuronal implementation af language compretension by relsing exclusively

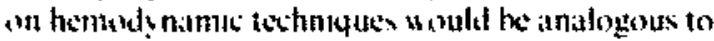
trumg to understand a plece of music by making an unserfers of the instruments that sonstitute the orchestra. What os mssing in such a statte description "sach instrument's melokly. and the way the dif. terent instruments interact. Similarly. in order to supture the fast dynamies of the train's language network. the information stained from PET and MRI studies needs to be complemented with Information derised from EEG and MEG. which recond neufonal actis ity on a millisecond time scale.
This chapter aims at providing a literature review of the rapid, oscillatory changes that are present in the EEG or MEG signals while subjects perform a variety of language comprehension tasks. In the following section we briefly indicate why these oscillatory changes are considered to provide a window onto the neuronal dynamics of the brain's language comprehension system. In addition. we delineate a general methodological framework for analyzing oscillatory brain dynamits. In the section "Experimental data." we teview the available experimental data, and the "Discussion" section contains a discussion of the datta and some consluding remarks.

\section{Methodnlogical framework}

\section{Neuromal synchronization, functional networks, and} the integration of information

One thing that has become very tlear on the hasis of PET and PMRI studies is that a oncto-one mapping between a hrain area and a specilite componem of a cognitive function is very often far too simplistic. Imaging studies often report atcivations of one and the same area during different tasks or cognitive runctions. This indieates that individual cortical areas can be recruited dynamically in more than one functional network (Mesulam, 1998). This raises the question of how. for a given function it.c., language comprehension). the dynamic recruitment of the participating cortical and subcortical areats takes place Another. yet related. question is how different sources of information te,g. information about phonology. syntax. or semantics). that are stored in different parts of the network. are integraled in order to form a coherent representation of the messige that is conveyed hy the speaker.

An atnswer to both these questions may he found in the patterns of synchronization and desynchronization of neuronal activity. Over the last 15 years evidence has accumulated that ide isynchronization is related to the coupling and uncou. pling of functional networks in the brain isec. c.g. Pfurtscheller and Berghold. 1989: Singer. 1993. 1999: Pfurtscheller and Neuper. 1997: Pfurtscheller 
and Lopes da Silva, 1999b: Varela et al., 2001, and many more). The idea is that synchronous. repetitive tiring of neurons facilitates the activation of functional networks because it increases the probability that neurons entrain one another in synchronous tiring (e.g. Konig and Schillen. 1991). In addition. elements pertaining to one and the same functional network are identifiable as such by virtue of the fact that they fire synchronously, at a given frequency. This frequency speciticity allows une atnd the sime neuron tor neuronal pool) to partecipate alt ditferent times in different represenlittins. Hexces syachronous oxillations in al wide tange of frequencies are considered to play a cruclat folte its linking atreas that are part of one and the sitme finctionat network. Importantly, in Ithditun to recruiting all the relevant network ekments. omillotlory meuromal symthrony would also verve so houd together the information that is represented in the different elements. ats was elegantly demonstrated in a seminil paper by Gray and Sinter iGials ct al. 1989). Fries recentls proposed a thople. set powerful. mechanistic account of this (r-citlled hinding-by-synthrong hypothesis I fries. $20 t 5 \mathrm{~s}$

\section{Quantification of neuronal synchronitation}

The yuestion is then. how can we obtain informition about the rapidly changing patterns of stnchronization and desinchronization of neuronal detis ity? The fast temporal dynamics of neural aewivity cian be captured by imaging methods with at high temporal resolution such is EEG and MFG. The compuation of exent-related potentiats or went-related lislds (ERPS ERFs ${ }^{\dagger}$ ) has proved to be particulatrly fruitiul in prosiding tine-grained infermatisn about the time course of subcompo-

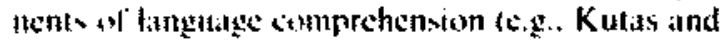
Hallyard. 1989). Hageont et al. 19931. Howerer. in

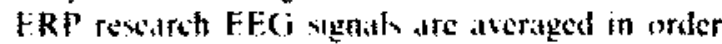
to tmprove the stgnat-to-notse ratto. This averaging procelure destroys any temporal structure of the single EE(i traces that is not phase locked to

Trentarke readabilu. we will veak stout EEG and ERPS in the remstuder of the test. Put the agamentation dpplics

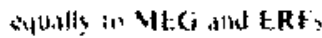

the eliciting experimental event. Hence, oscillatory phenomena that are not precisely phase locked to the eliciting event are severely attenuated, if not completely cancelled, when average ERPs are computed (Pfurtscheller and Lopes da Silva. 1999 a).

The canceling of oscillatory activity as it occurs in ERP computation thus hampers our view on the dynamic interactions of neuronal ensembles both within and between brain areas. Therefore, other methods than traditional ERP analysis are needed to optimally eaplure (de)synthronization phenomena.

Which analysis procedures would be adequitte then for studying thanges in oscillatory synchrony" Here we must make a distinction hetween locial synchrony. i.t. synchronization wishin a node of a functional network. and long-range synchrony, i.e., synchronization hetween different nodes of a network.

Loeal synchronous activation of a large number of neurons will, by virtue of the spatial summation of pestsynaptic polentials. result in an increase in amplitude of the resulting lick potential at the recording site. It follows that an increas in focal synchronous oxcillatory tiring of a neuronal population will lead to an increase in amplitude of the scalp-recorded EEG oscillations. Such amplitude (or power, i.e.. squared amplitude) changes should he studied at the single trial level talthough the average atmplitude. or power change. can subsequently be computed over trials). Different methods for studying event-related power changes have been used in the literature: the most widely used are event-related band power analyses like erentrelated desynchronization (ERD; Pfurtscheller and Aranibar. 1979: Pfurtscheller and Lopes da Silva. $1999 \mathrm{~b}$ ) or induced band power (1BP: Klimesch et at.. 1998). single-trial wavelet analysis ITallonBaudry et al.. 1998), or the more recently proposed and more sophisticated multitaper analysis (Mitra and Pesaran. 1999).

In contrast. activity in distant neuronal popula. tions is. for the largest part. not picked up by one and the same clectrode or gradiometer. but by different electrodes gradiometers. Therefore. the above-mentioned methods do not apply. Here the relevant information lies in the phase relationship 
between the lield potentials recorded from or above different areas. An increase in synchrony will fogically lead to an increased stability in the phase difference of two oscillatory field potentials. which is typically termed coherence (see. e.g., Varela et al., 2001). This can be quantified using methods such as event-related coherence analysis (Andrew and Pfurtschetler, 1996: Nunez et al.. 1997 ) or phate-locking statistics (Lachaux et al., 1999). It should be mentioned that besides power and coherence changes, other event-related thanges in axcillatory FEG MFG inctivity could be me:tninglul in studying the nearal hasis of cogmlive tumelons (sec Makeig et at. 2004 for an excellent averview of potentiatly relevant phenomenil). For inslance. there have heen several reports wn exeul-related phase resetting ahe phase realganmettl. wer trials, of ascillatory activity with ferpet $w$ an experimental event. e.g., Braeutigam el al. 2001: Rizzuto at al. 2003).

As ne will see in the literature review presented in the next section. a majority of the staties aderesing the neuronal dy namies of kanguate comprehemsen hase concent rated on andlyzing power shanger. Thus there is a bials toward hat synthrontratuon phenomena fi.c.. sanchrony withir a neide of a lunctional network) that the reader should keep in mind while going through the literature. In addition. studies addressing both power and cokerence changes during language comprehension atre completely lacking. We atre con inced that such studies are highly desirable in order to arrive at at full destription of the neuronal As numics of the language comprehensiun precess,

\section{Experimental data}

In sam. the ahore distassion veggest that at topauraphucal atmalsos of cuent-related shanges of power and coherence in owillatory EEC ackivty recorded durng a range of languitge comprehension tasks might to informative with tespect to the neuronal dynamies if.e. synchronization and desynchronization) that are instrumental in the coupling and uncoupleng of synchronous functonal networks. This funkoupling, in turn. serves to revrutt the different elements of the brain's language network, and to integrate the information that is represented in each of the network elements.

Below we present a review of the literature that aims at identifying the neuronal dynamics observed in a wide range of language comprehension tasks, with an emphasis on our own work. Note that this review is not fully exhaustive. However. the large majority of the relevant literature is addressed, and as such the review is representative for the developments in the field. In our opinion. such al comprehensive literature review is very useful at this point in time, as we signal a trend toward an increasing number of papers that inderess the neuronal dynamics underlying language comprehension in recent years. while no comprehensive review papers are available yet.

Power and coherence changes in oxcillatory neuronal responses during language comprehension have been observed in four different frequency bands: theta $(4.7 \mathrm{~Hz})$, alpha $(812 \mathrm{~Hz})$. lower heta $11318 \mathrm{~Hz}$ ), and gamma (athove $30 \mathrm{~Hz}$ ). The elfects can roughly be subdjvided into effects related to memory retrieval operations during fanguate comprehension. and effecis related to unification of linguistic informattion. Where possible, we will try to isolate time frequency components (by which we mean robust eventrelated changes in power or coherence) that can be identified on the basis of their scatp topography. frequency band. temporal evolution. and the extent to which they can be modulated by experimental manipulations.

\section{Oscillatory neuronal dynamics related to the retrietal of lexical information}

A number of studies suggest that oscillatory neuronal dynamics in the theta frequency range ate involied in the retrieval of lexical semantic information. In an initial study (Bastiaansen et al.. 2005. we examined EEG nower changes in a range of frequencies from I to $3 \mathrm{n} \mathrm{H} z$ while subjects read a short story. Power changes were averaged selectively for open-class $(O C)$ words ie.g. . nouns. verbs. and adjectives). which carry most of the semantic information in a sentence. and for closed. class $(\mathrm{CC}$ ) words fe.g. articles. determiners. and 
prepositions). which carty much less semantic inFormation, but rather serve as "syntactic glue" at the sentence level. As Fig. 1 shows. both OC words and $\mathrm{CC}$ words elicited a power increase in the theta frequency range, together with decreases in the alphat and beta frequency ranges. roughly in an interval of $100600 \mathrm{~ms}$ after word onset. The $O C$ words generatly elicited stronger power changes. Interestingly however, while the seatp topography of the alphia and beta responses was qualitatively simitar, in the theta frectuency range we observed a yuafitative diflerence thetween $O C^{\circ}$ and $\left(C^{\prime}\right.$ words. Wheteas huth types eliecited at theta power inerease ancr left escopitial and micitrontal areats, the $O C^{\circ}$ mords alkitunatly shided at power increase over leti temparil atrets, which wis mot abserved for the ('C wards fece Fig. 1). A regtession atatlysis vaned that this oflect was mot dependent upon werd length wis wort fregency. This lopographwill pattern comects well to existing hemodynamic data. The left occipital power increase may be related to complex visual processing either in Broca's area $18 / 19$ (see. e.g., Petersen et al., 1988: Indefrey et al., 1997) or in the fusiform gyrus (the putative visual word form area, cf. Cohen et al. 2000; McCandliss et al., 2003). Most interestingly however, with respect to the differential $(O C$ specific) theta response over the left temporal cortex. it has been shown that left temporal areas (more precisely, left posterior superior and/or midale temporal gyrus) are involved in lexical retrieval (see, c.g., Indeltey, 2004: Indefrey and Cutler, 2005). Therefore, the quatitative difference between $O C$ and $C C^{\circ}$ words led us to hypothesize that theta-band synchronization of neuronal atetivity is related to lexical-semantic retrieval

A subsequent experiment (Bastiaansen et al. submitted aimed at further testing this hypothesis. Subjects performed a lexical decision lask, in which they had to decide whether or not at visuatly

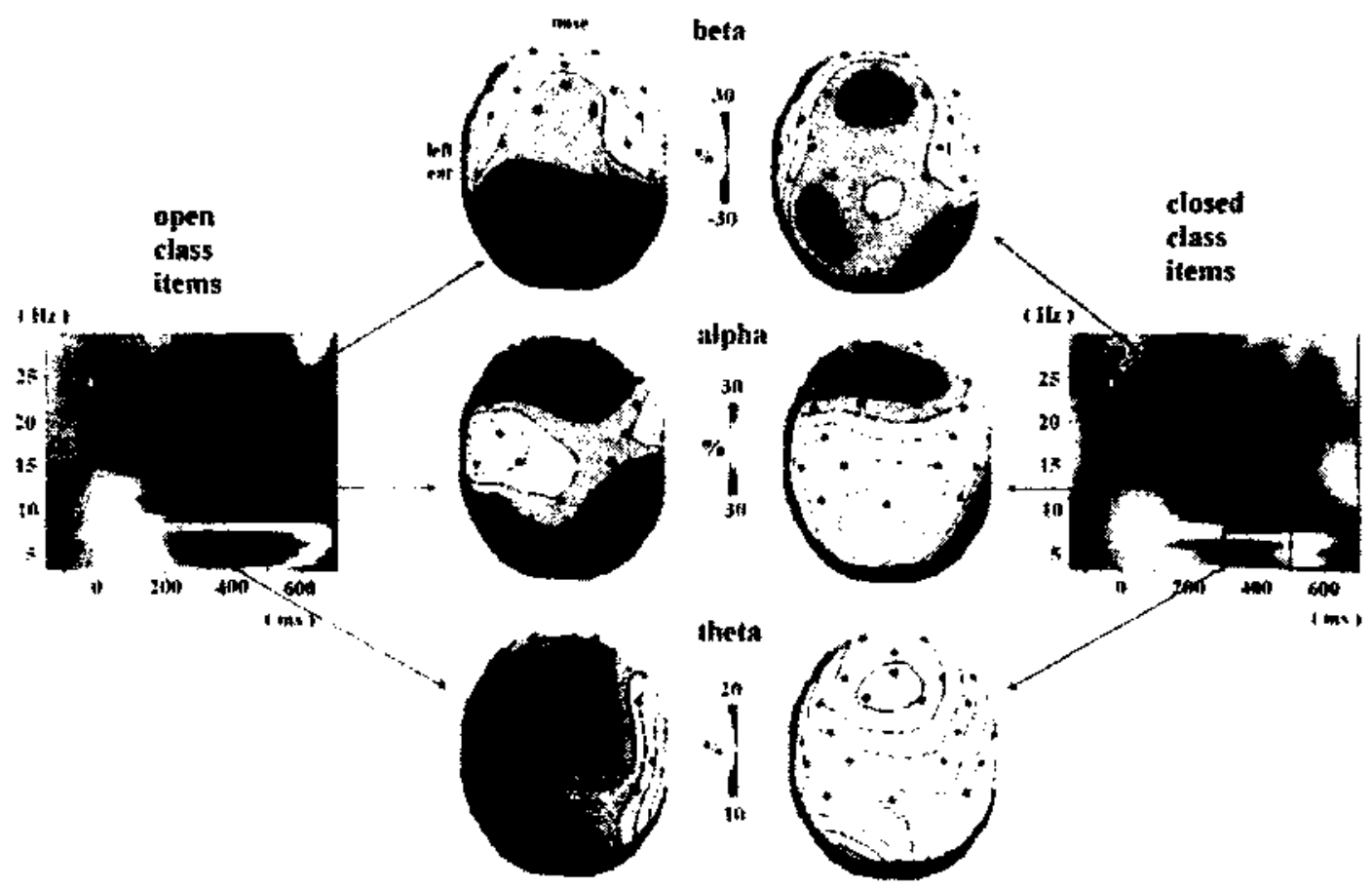

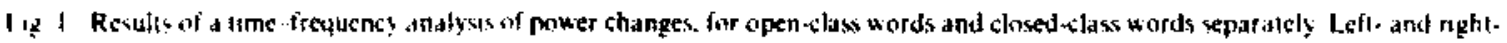

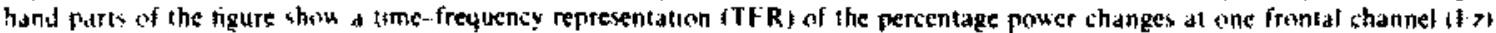

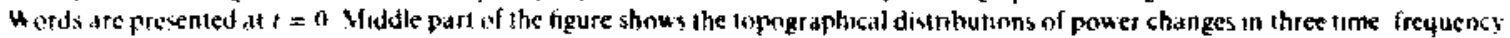

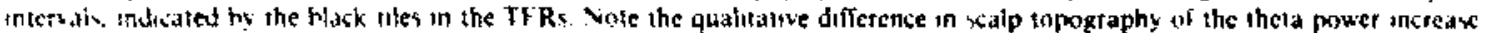


presented string 'of letters constituted a real word. Nonwords could be either pseudowords (phonologically legal, but nonsensical tetter strings) or tonsonant strings. Real words could either be nouns with visual semantic properties (i.e., referring to colors and shapes) and nouns with auditory semantic properties (i.e. referting to sounds).

Again, both sets of words elicited an increase in theta power and decreatses in the alpha and beta frequency ranges. And again. quatitatively different responses were found only in the theta band. where the fallowing double disionitition was found (see Fig. 2): Words with auditusy semantic properties shomed larger thelit power increases in electrodes werlyng the kelt additory cortex than in electrodes ancring the lelt vistal cortex, while the topposite paltern was liound for words with sisuat semantic properties. Note that, as both sets of words were presented visually, and were matched for length and frequency, they only differed in terms of semantic properties. We therefore concluded that the results of this study confirm the hypothesis that neuronal synchronization in the theta frequency range is involved in the retrieval of lexical semantic information. In addition, our data are in agreement with the hypothesis that spatially distributed functional networks form the basis of semantic representations, and that the topographics of these networks reflect the semantic propertics of individual items (for similar hypotheses. sec Pulvermueller, 1994, 2001: Martin and Chao, 2001).

While the above studies suggest a strong involvenent of theta-band synchronization in retrieving lexical-semant ic information, the neuronas]

\section{Theta (4-7 Hz) power changes}

a)
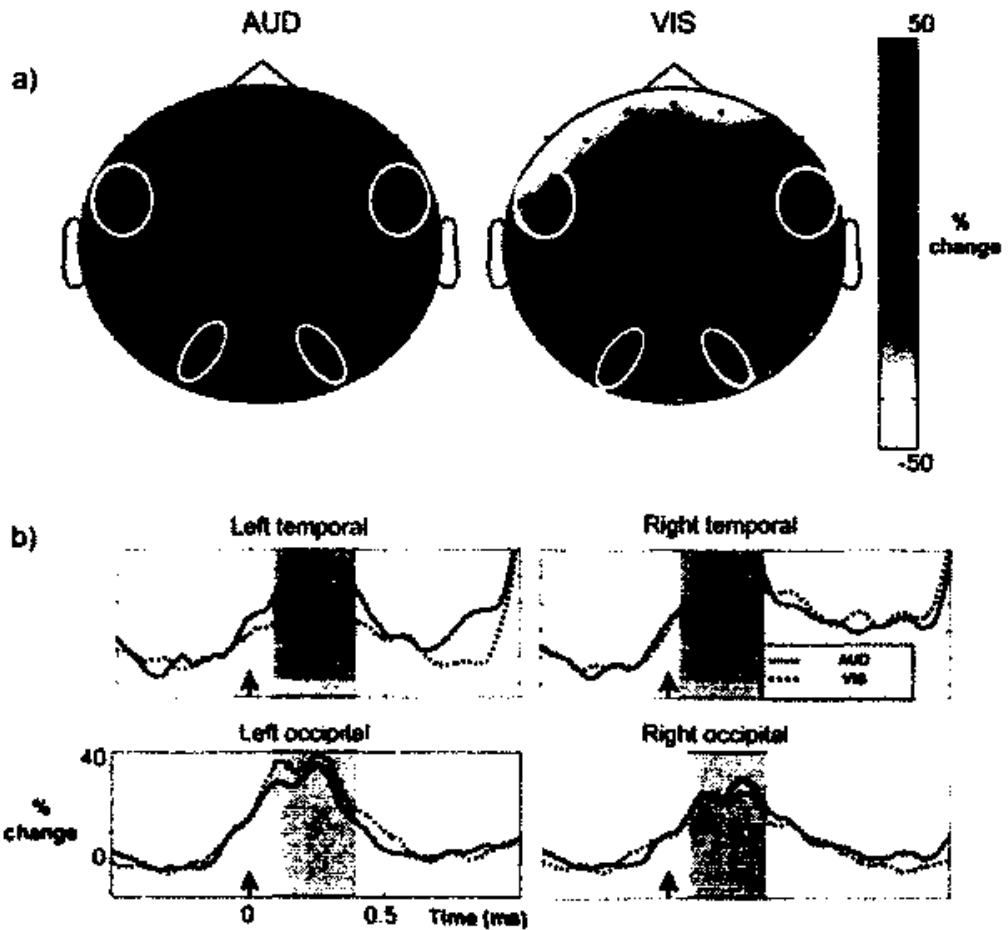

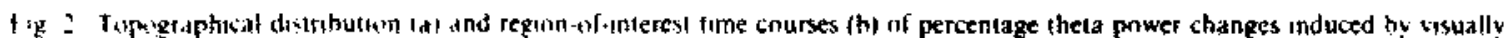

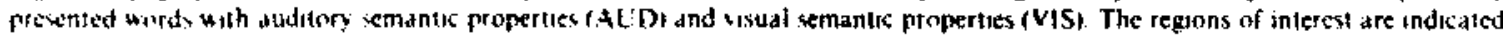
to the whitc ellinswi in tat Shaded dicus in ihi indicate the lime interval used far the slatislical analyses In the left hemishere, there in

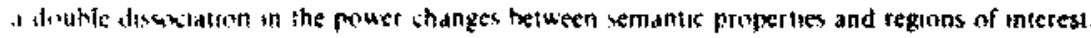


dynamics of language comprehension-related retrieval operations are certainly not restricted to the theta fricutency band. Other studies have related semantic memory operations to power changes in the atpha frequency band for teview, see Klimesth. 1999). For instance, in a study by Klimesch and colleigusis (Klinesth et al. 1997b) subjects were asked to judge whether pairs of words were semantacally related, and this was accompanied by power decreases in the (upper) alpha band. In anwher study liom the same group (Rohm et al.. 20(1). stthiccls had to lind a superordinate concept (t,e.. il scomantec retreval task) while reading sentences, and this wals accompanicd by a stronger alphit pouer decrease compared to a condition where only reading was required. In yet another study (Kfintesch et al. 1 1997a), subjects judged whether sequentrally presented feature concept pars were semantically congruent. It was found that only (upper) alpha power discriminated between good and poor performers. The distinction reported in this latter paper between upper and lower alpha frequency bands seems to hold over a range of empirical data showing that different patterns of alpha desynchronization can be observed when the broad alpha frequency range is subdivided into lower and upper alpha bands on the basis of individual alpha peak frequency (see Klimesch. 1999 for review). The lower alpha band has been shown to be more sensitive to general task demands such as attentional processes. while oscillatory neuronal activity in the upper alpha frequency range hikely reflects specific task requirements. In strong support of these findings. it has been demonstrated that event-selated power changes in the lower and the upper alpha frequency bands ancreasingly dissocjate as task demants inerease f Fink et al. 20065 .

It should to noted. finalls, that in many of the stuties by Klanesch et al. thut not the ones cited whowel the term semantic memory is often used in the sense of declarature fas opposed to epusodic) memory. Athough this is perfectly wald terminology. there is a potentiaf confuston with the term "semantic" as it is meant in language comprehension theorles. There the term semantic is used in its mote narrow sense. referring to the meaning aspect of words lats opposed to syntax. phonology. etc.). This terminology issue should be kept in mind as one reads through the literature.

A few studies have reported effects of memory retrieval in higher frequency bands (beta/gamma). For instance, Weiss and colleagues (cr. Weiss and Mueller, 2003 for review) found different coherence patterns in the lower beta frequency range (roughly $13-18 \mathrm{~Hz}$ ) between concrete and abstract nouns, and between concrete nouns and verbs. Pulvermueller et al. (1999) contrasted nouns (which were taken to have predominantly visual semantic properties) with verbs (presumed to have movement-related semantic propertues) in a lexical decision task, and found power decreases in the gamma frequency range compared to basclinc. which were smaller for verbs than for nouns at central electrodes, but straller for nouns than for verbs over occipital electrodes. These data were interpreted to reflect different network topographics that followed the semantic properties of the stimuli (much as the above-described difference in theta topography between auditory and visual semantic properties). However, the reported effects consisted of gamma power decreases with respect to a prestimulus baseline. This is in contradiction with the general notion that networks emerge through increased synchrony (although the alpha frequency range may constitute an exception, see. e.g., Pfurtscheller, 1992; Pfurtscheller and Neuper, 1994 for relevant data, Bastiaansen et al.. 2005 for a brief discussion, and Steriade et al. 1990 and Lopes da Silva, 1991 for a possible underlying physiological mechanism), which, in scalp recordings. should be reflected by power increases rather than decreases compared to baseline (cf. Varela et al. 2001: Bastiaansen and Hagoort, 2003).

\section{Oscillatory dynamics related to unification operations in language comprehension}

As sentences extend over relatively long time periods. maintaining the workıng memory (WM) trace of the linguistic input is a prerequiste to performing unification operations. In addition to retrieval operations. theta-band changes in neuronal synchrony also appear to play a role in such WM processes. For example, theta power (Bastiaansen et al., 2002a) and coherence (Weiss and 
Mueller. 2003) linearly increase over the course of correct sentences. In addition. theta power is larger over the frontocentral midline following words constituting syntactic (Bastiaansen et al., 2002b) and semantic (Hagoort et al., 2004; Hald et al. 2006) violations in sentences (see, e.g., the righthatnd part of Fig. 3). These effects were interpreted to be related to the larger demands that they impose on verbal WM (Hald et al., 2006). Also, theta coherence is laryer following WM-demanding object-relative vs. subject-relative clauses (Weiss et al., 2005). A clear relationship between theta-band oscillations and WM has atso been found using intracranial recordings in humans (Raghavachari et al., 2001; Rizzuto et al., 2003).

There is however more to unification than just maintaining the input in WM. Unification requires the active manipulation of phonological, syntactic. semantic. and likely atso of pragmatic information, resulting in a message-level understanding of

Time-frequency analysis

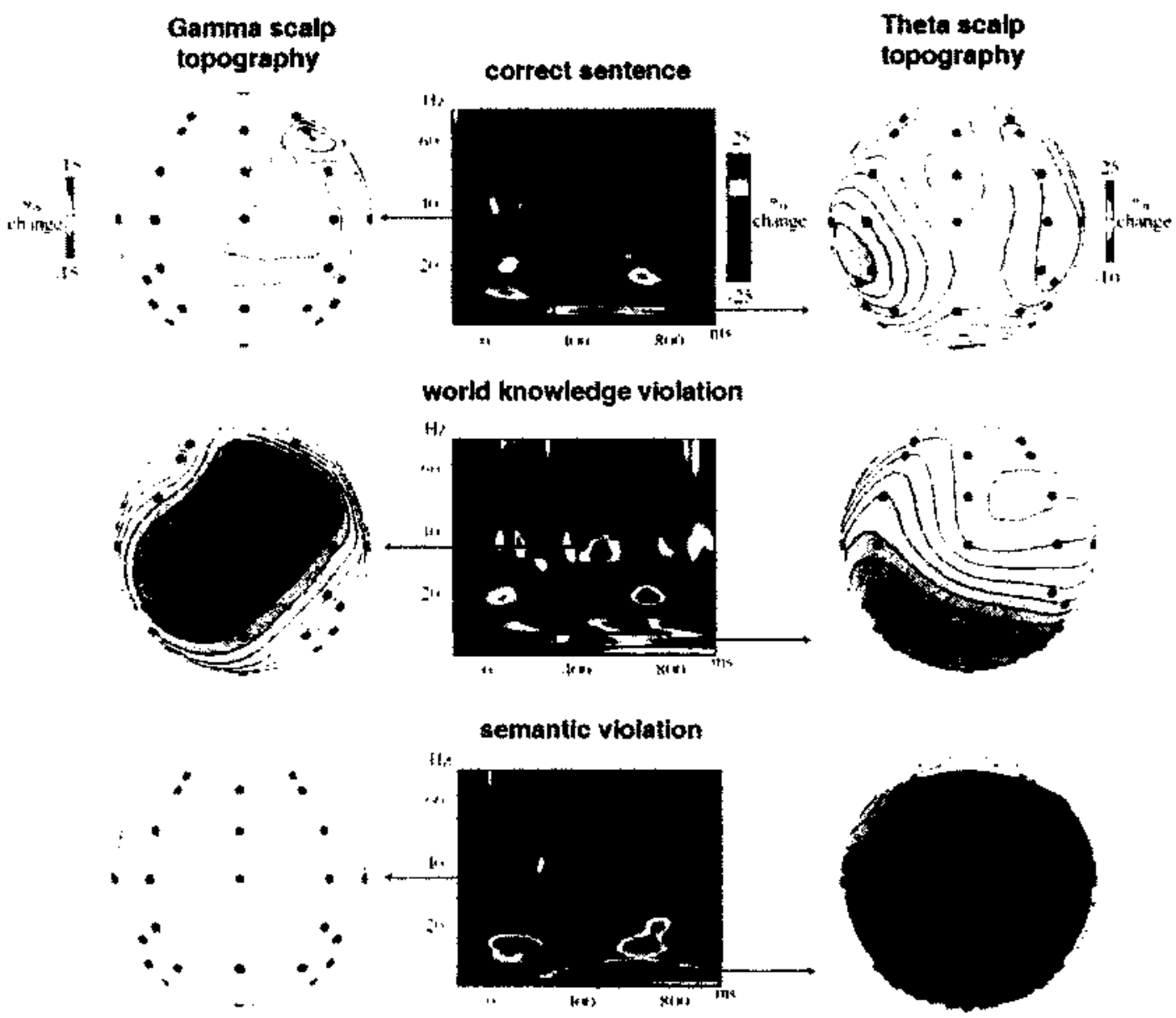

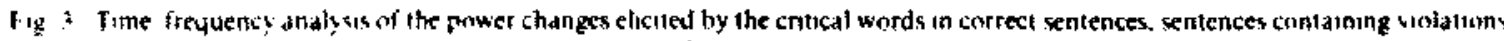

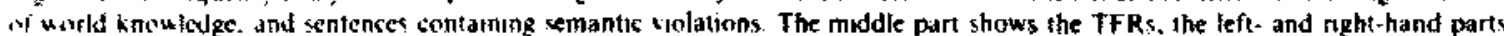

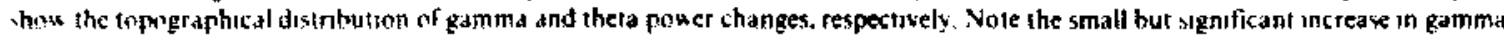
poruer aver lateral frontal areas in the correct conduon. the strong gamma power increase following a world knowledge violation, and

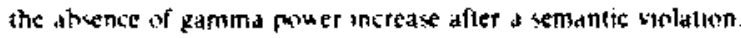


the linguistic input. So fur. experimental research into the neuronal dynamics of unification operations have concentrated on semantic and syntactic unitication only.

\section{St'muntic unification}

Recently we have addressed the oscillatory correlates of semantic unifieation in the following way (Hagoort et al.. 2004: Hald et al., 2006). Subjects reid the following three versions of sentences such as: "The Dulch Irains are wow/whte/sour and serv cruwded." In fact. Dulch tratins are yellow. atad therelore the lirst version of this sentente is the currect wentence condition. However. the fingussite meanung aspects of the alternative color lerm white apply cyutatly weil to trains as the predicate wellen: It is world knowledge athout tratiss of Holfiand that make the seeond version of this sentenes filise the world knowledge volation comditiont. This is difterent for the third cersion. The core meaning of vour is related to tiste and fincl. Finder standard interpretation conditions il preticite requires att atrgantent whose semantic feiture onerlap with that of its predicate. For cehate vath o trans. this is cicarly not the citse. smee wemantic leitl ures related lo taste and food do net apply to the materials that trains are made of. Thus. for semantic-internal reasons the third sentence is an outright semantic violation condition.

The results itre presented in Fig. 3. In the correct sentence condition, where normal semantic unitivittion takes place. we obsersed a small increase in Yammal pouer relative to bascline in response to the sritical word fe.g. yellow). This ganma nower increalse wis much stronger in the sorld knowldige wolation condition. where semantic unificiron ss difficult hut not impessible. In the semantic solutlow conditlon houster, where semantic unj-

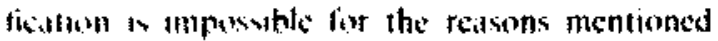
shous. fhe gattumat pouser increitse was absent.

The parantetre relation between semantic unfisatkill and gamma power described above suggests that gamma oscillations are functionally related to semantc unification operations. Several other studies support this notion. First. gamma coherence is larger for semantically congruous than for incongruous sentence endings (Weiss et al. 2003). In it different approach. san Berkum et at. (2004) studied the effects of referential success. referential ambiguity, or referential failure in a sentence. and found a drop in gamma power following the ambiguous and failing reference conditions, which render semantic unification problematic.

A final link between gamma-band synchronization and semantic unification operations was reported by Braeutigem et al. (2001). These authors report an increase in phase-locked gammaphaselocked gamma power in response to semantic violations in sentences relative to correct control sentences. Thus, the results go in the opposite direction (larger gamma power for violations) compared to the three studies discussed above. However, this may be partially explained by the difference in analysis methodology: only phaselocked power changes were considered in this paper, which suggests that some sort of phase alignment or phase resetting occurred in the gamma band as a result of the semantic violation. Note that phase resetting has also been reported to occur in the thetat frequency range during a WM task (Rizzuto et at.. 2003): so the phenomenon is likely to hate functional significance in a range of cognitive latsks.

Taken together. the above studies lead us in hypothesize that neuronal synchronization in the garmma frequency range is in some way related to the unification of semantic information is implemented in the brain.

\section{Sinutic unification}

The neuronal dynamits of syntactic unification hate been addressed in a number of different experimental paradigms. For instance. Haarmann et al. (2002) used sentences in which EEG coherence was examined in the interval between the object and the main verb of a sentence (the so-called filler gap interval. cf. Haarmann el al. 2002 for details). Although this filler gap intervil places it relatively large demand on verbal WM. the gap lilling that the reader has to perform on-line can the seen as a syntactic unification operation. The authors found increased coherence over many salp areas in the sentences containing a filler gap interval compared to nonfiller sentences. in the lower beta frequency range (roughly $1518 \mathrm{~Hz}$ ). This increased coherence is indicative of an 
increase in long-range neuronal synchronization during the syntactically more demanding filler sentences. A study by the Weiss et al. (2005) compared EEG coherences during sentences in which the subject of the main clause is also the subject of the relative clause (so-called subject-relative (SR) sentences). with EEG coherences during sentences in which the subject of the main verb is the object of the relative clause (object-relative (OR) senfences). SR sentences are syntactically relatively simple. and hatve a high frequency of occurrence in everyatily language, whereats OR sentences are kes frequent, syntiktically more detnanding. and plicte al larger hacd on verbal WM. The authors showed thit ancreased thetal and gamma eohersoces uere assoliated with the higher WM load.
The effects of syntactic complexity (which become most evident in the time period just following the relative clause) however were expressed in the lower beta frequency range $(13-18 \mathrm{~Hz}$ ). In a similar type of experiment with Dutch subjects and stimuli, we are currently investigating power and coherence changes of the MEG between $O R$ and SR sentences, and between sentences with rightbranching ( $R B$ ) relative clauses compared to the syntactically more demanding center-embedded (CE) relative clauses. Preliminary results from this experiment suggest that $C E$ sentences elicit larger $M E G$ power in the (lower) bela freyuency range (in this case, $1525 \mathrm{~Hz}$ ) compared to RB sentences (see Fig. 4). Analyses of the coherence data. and of the SR-OR comparisons, are still in progress.

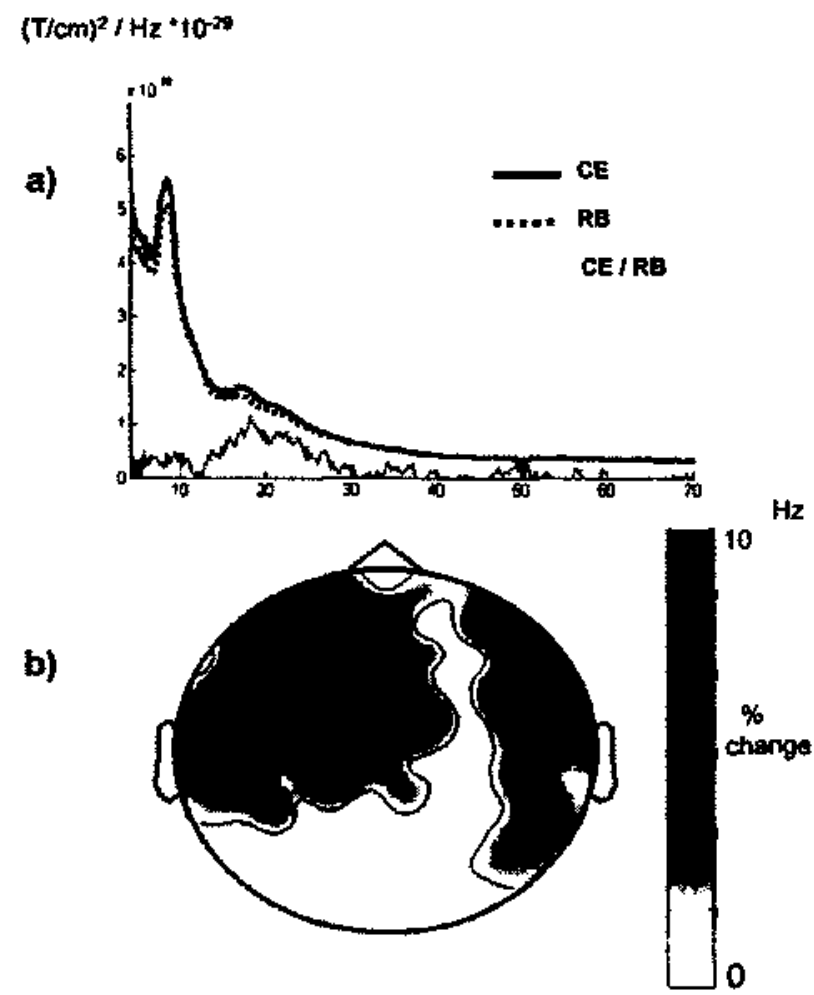

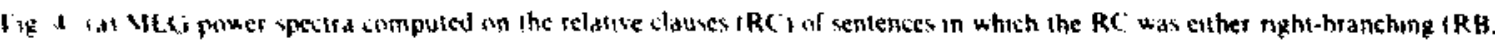

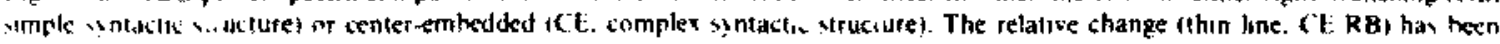

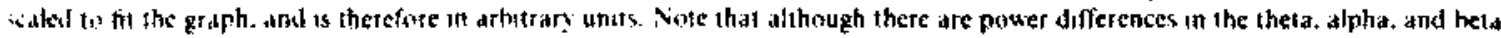

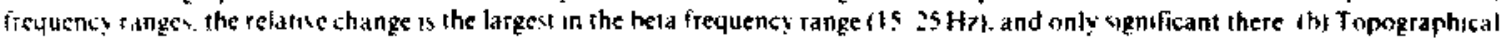

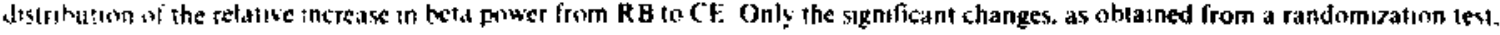

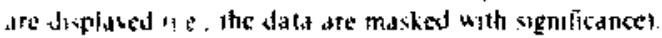




\section{Discussion}

As we have seen in the previous section, the general pattern emerging from the experimental data shows a clear and robust distinction in network dynamics between memory-related processes lsynchronization of neuronal activity within and between network nodes in the theta and alpha frelutency rangesil and semantic and syntactic unilication-related processes (beta-band and gammahatnd syencturonizationt. Thus, it appears that there is a wellotharactetized pattern of frowuency spexifort an the observed lime frequency components. Anuher itspect of the atailable experimental data

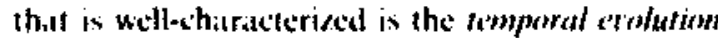
of the atiflesen escillattory responses: the large milutily of the ascilfatory responses that have heon itworted arc toncentrated in roughly the tirst stll mis after word presentation. whether it be in sinlated uord stusties or in sentence materials. This time intersal is known. on the basis of a large body of behas lorial and ERP widene. to be crucial in lanezitge comprothension, Alsis, lhere sems to the al larece comststenes oner studies in the direction of the anselutution af pasuer and coherence changes. which is different for the different irequency bands. In general. theta and gamma power and wherence increase relative to baseline. Alpha powar wenerall decreases relative to baseline (alpha coherence has not been studied). whereits the werill pittern for teta-tand effects seems to be thit theta pouer decreatses. while beta coherence increitses relattise to baseline thut there are a fou exceptions to this latter patterns.

In aspect of the nscillatory dynamies during language comprehension that is less well charactertied is the menelraphical distribution of the repurled effects. This mas he partialls due to the fact that in the early dass of time lrequency inalysis of

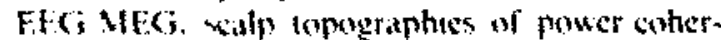
thes changes were often not reporled. perhaps to redact the relatively high computalional load that somes with time. Frepuencs analyses. perhaps also heciuse it was not comsidered to be of crucial importance. In addition, wh coherence analyses it is sernetimes difficult to point to a clear topographical distfibution in the pattern of interactions between hrain areas. However, when studied. the topographical distribution of oscillatory dynamics is often not very consistent across studies. This makes it difficult to connect and integrate the increasing knowledge about the dynamics with existing knowledge about the structure of the brain's language network as obtained from hemodynamic studies. Possible avenues for improving this situation may be (1) the use of advanced source reconstruction techniques that are developed specifically for the localization of oscillatory activity. such as dynamic imaying of coherent sources (DICS: ef. Gross et al., 2000, 2001. Hoogenboom et al. 2006), or (2) the simultaneous measurement of EFG and IMRI, where recent developments have made it possible to correlate oscillatory ativity in distinct frequency bands with MRI BOLD changes (sec. e.g. Gioldman et atl. 2002: Laufs el al., 2003; Parkes el al., 2006).

\section{Memory}

The neuronal dynamies that have been observed in relation to memory retrieval operations in the context of language comprehension ate chatatcterized by synchronization of neuronal activity in the theta frequency band. and desynchronization in the alpha band. This pattern of results connects well to the results that have been obtained outside the domain of language. In a large number of experiments that use domain-general memory tasks. theta and alpha power changes have been related systematically to the encoding and retrieval of epitodic and declarative information. This has then observed both in soalp EEG recordings isec Klimesch, 1999 for at comprehensive reviewl and. as far as the theta-band results are concerned. in intracranial recordings in humians (Kakana et al.. 1999, 2001: Caplan et al., 2001).

With respect to theta-band acivity. there is an even larger hody of literature. based for a large part on animal studies, that supports a role for thela in memory operations (for extensive review sec. e.g. Miller (1991)). In this literature. theta-band oscillations are considered to estab. lish dynamic links between the neocortex and the MTL memory system. Eichenbaum et al (Eichenbaum et al.. 1994, 1996). amongst others. 
have proposed that neocortical association areas maintain short-term memories for specific iterns prior to MTL processing, and eventually provide the tinal repositories of long-term memory. The latter idea is consistent with that proposed by Miller (Miller, 1991), that "the hippocampus (...) acts in some ways as an "index to memories, the cortex being, as it were, the 'book' to which this index refers" (Miller. 1991, p. 159). Similar, athough slightly different, ideas have been put forwatrd by Treves and Rolls (1994). Accordtog (1) Miller (1991), the Itansfer of informaItun belween the MTI, system and tortical issiciallem areals maly well to mediated by thythmic actislly in the thetil frequency range fece Hatstiatarsen and Hagerort, 2 (n), 3 for a mote detailed discussitunt.

An monertant implication of Miller's notion of telf-orgatnising. resomant theta-synchronized foops beswen the MTL system and the neocortex is that studing the raletivits of theta at the "cortical ens ${ }^{*}$ af the lowp te.g. with stalp EEG MEG) latght provide us with a windos on the MTL comerahation to different types of menory procexise. It is therefore not anlikely that the thetit poust responses that hase been observed in the context of language comprehension are also an expression of synchronized actisity in corticom hippocampal cireuits. This notion is at least indirectls supported by a number of studies that have und intracrinial rewordings directly from the human WTL daring language comprehension tasks. These studis have reported nepatise deflections in the anterior MITL that show a similar reactivity as the sialp-recarded N4mo isuch as latfer amplituake for stmanticalls unrelated words. larger amplitudes for highly imageable words. atc. McCarths et all. 1995: Nobre and MoCarthy. 1495: Heckess at al. 2002: Klaver at al. 2005: Hescer st al. zoms

In sum, we might cinclude from the above that the mechatnems anvolsed in the retrieval of fexcat information are of a fomain-general nature. ic. the neuronal dinamies by which the hraw 's language network eperates are not specific to biaguige comprehension. but apply more generally for memory retriesal (which has ben extersicely studied in animalst. However. since this mechanism is apparently also involved in language comprehension it does add to a better comprehension of the dynamics of the brain's language network.

The observed alpha power changes are more difficult to relate to a neuronal circuitry involved in memory. Traditionally, alpha-band oscillations are associated with thalamo-cortical information transfer. and, at the functional level, with the transmission of sensory and motor inpul to the cortex, and with attentional modulation of this transmission (sec, e.g., Skinner and Yingling, 1977; Lopes da Silva, 1991: Brunia, 1999; Bastiaansen and Brunia, 2001). In this context it is interesting to note that alpha power has been sensitive to linguistic manipulations mainly in those situations where a secondary task was used (e.g.. linding a superordinate concept, or performing a semantic judgment. etc.. see subsection "Oscillatory neuronal dynamies related to the retrieval of lexical information"). In those studies, differential effects are usually found for the lower and upper alpha batnds, where the lower alpha band is generally modulated by generit task demands such as attention, and the upper alpha band is sensitive to specific task demands. In addition. Ihe eventrelated power changes in the lower and the upper alpha frequency bands increasingly dissociate as task demands increase (Fink et al. 2005). This data pattern seems to suggest that both alpha subband ranges are sensitive (though in different ways) to secondary task demands. These tindings stand in sharp contrast to our own work. where we typically ask subjects just to read for comprehension. In those studies. we have not observed a systematic modulation of (either upper or lower) alpha power as a function of linguistic manipulations, which might suggest that the alpha band reactivity observed during language comprehen. sion is not necessarily related to the comprehension process per se. but to general attentionat levels (lower alpha) and the specific behavioral consequences of the language comprehension process (upper alpha). This explanation is very speculative though, and we doubt that it could account for all the findings described in subsection "Oscillatery neuronal dynamies related to the retrieval of lexical information." 


\section{linfication}

As said, syntactic and semantic unification operations during language comprehension are acconpanied by neuronal synchronization in the higher trequency ranges (beta and gamma). So far, syntalctic unilication has been associated exchusively with heta-band synchronization, whereas semantic unilication has been alsociated both with betaand gitmona-band synchronization. Although this is suggestive of a qualitative difference in the dyatatnits of syntitctic and semantic unification. ito sungte study has itdeteswed both types of operitums whin the sime sample of subjects. In etditurll. the neurenatl dynamics of syntactic uni-

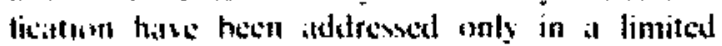

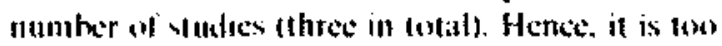
catrly to drats ally lifm conclusions regaltding it pensible ylatsativice difference between syntactic and remlatitic anitication dynamics on the hasis of the cristing dittabise.

The integration. or hinding, of information irum diflerent hrain areas has repeatedly treen atvisitted with neuronal sinchronization in the Eamms freytents range outside the domatin of longtage comprehension. For instance. gammit whehronization has been shown to play a role in leature binding in the tisual system (c.y.. Gray and Singer. 1989: Roeltsemal et al. 1997: Fries et at.. Jolat: see. cig. Singer and Gray. 1995 for a resiew). and is subject to attentionat modulation IFries at al. 200ib) in addition. wammit-band anchromization has been related to top-down inlegrative processes in perception ie.g. Rodriguez ct al. 1999: Tislon-Baudry and Bertrand. 1999). Theretore the observed relitionship between tatmarat-band ynchronizatum and sematntic unilitatwon aperations tits well wthen the harger context if the intentatise role that gammathand neuronat

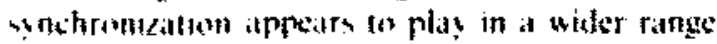
of conguthe dombins

Such a connection wo doman-general processes is less cleaf for the effects observed in the hetit frequency range. Traditionalls. beta-band activity has teen related to the planning and execution af' mowements (sec, c.g. Pfurtscheller et al.. 1996. 19981. Where the byical pattern is a desynchronization of beti-band activity before and during movement execution, and a somatotopically organized beta synchronization after movement offset. However, as we saw in subsection "Oscillatory dynamics related to unification operations in ranguage comprehension," beta reactivity is a robust phenomenon in language comprehension tasks, in the sense that it is observed during a variety of tasks, with different analysis procedures and in different laboratories. It is therefore likely that neuronal synchronization in the beta frequency range is truly instrumental during linguistic unification operations. although its exict role remains unclear al present.

\section{Conclusion}

We have provided an overview of the neuronat dynamics that can be observed during a wide range of language comprehension tasks. Overall, the experimental data indicate that the two components of languige comprehension. namely. the retrieval of lexical information from the mental lexicon and the absequent unilication of semantic and sybtatec inforntation, yicld distinct patterns of synchronization in the bratn's language network: retrieval operations ure associated with neuronal dynamics in the theta and alpha frequency ranges, whereats unification operations are associated with neuronal synchronization in the beta and gamma frequency tanges. As such. the general pattern of results suggests that at the level of the dynamic neuronal mechanisms by which the brain operates during language comprehension, domain-general processes are operatite fi.e. the observed mechanisms are not exclusively engaged by linguistic processing. but are also ohserved in other cognitive domains). This apposes to the representational level. where there is a relative domain-speciticity for language comprehension i.e. thefe are brain areas that are partly dedicated to the storage and manipulation of lingusstic information. as evidenced by hemodynamic studics.

We conclude that it is possible to capture the dynamics of the brain's language network by a careful analysis of the event-related changes in power and coherence of EEG and MEG data in a 
wide range of frequencies. in combination with subtle experimental manipulations in a range of language comprehension lasks. It appears then, that neuronal synchrony is a mechanism by which the brain integrates the different types of information about language (such as phonological, orthographic, semantic, and syntactic information) represented in different brain areas.

Finally. we led that a word of caution with respect is the stbove conclusions is appropriate. conpared to the more slassical FRP approach, indalyrify the awillatery brain responses in relia (won to langtatece is still in its infancy. Redalively lew studies hate been dond. and the functional shatraterestiss of the ascitlatery bratn respenses reporled in litnetrige studies are not yel well understoul. Neveriheless, we helieve that analyzing oscollatury bratu dynatmics hats yuite some mileage that molizates ferther stadies. We hatse here prosicted a pischolinguistically and neurobologically plausible framework for stuctying the neurosognifir on of linguilute. In this framework, an importint distinction is mikle totwen memory and aniliciation operations. Basted on a resjea of the literatute. thuf eurrent worting hypothess is that syehronisation in the thet irequeney itnd. possibls, dessnchronication in the alpha frequency ranges are mechunistically insolved in memory retries al. Initication operations. on the other hand. afe thought to he associated with synchronization in the betal and gatmmat frequency bands. So latr. se hate not seen any combincing es idence that this generalization sould he diflerent for local syenchroms a retketed in power shangest. or in synchrontoling altisits in distitnt atreats tehanges in coherencel. Howserer, we are the lirst of admit that mish more work is nected to get a firm grasp "wh the lametwilal signtiliciance of the different on-

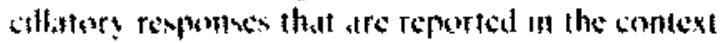

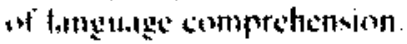

\section{Itbreviations}

BULD blood oxygenation levet depend$\mathrm{D}) \mathrm{CS}$ ent response dynumic imaging of coherent sources

$\begin{array}{ll}\text { EEG } & \begin{array}{l}\text { electro-encephalography } \\ \text { event-related desynchronization } \\ \text { event-related synchronization }\end{array} \\ \text { ERP } & \begin{array}{l}\text { event-related potential } \\ \text { functional magnetic resonance } \\ \text { imaging }\end{array} \\ \text { FMRI } & \text { magneto-encephalography } \\ \text { MEG } & \text { positron emission tomography } \\ \text { PET } & \text { working memory }\end{array}$

\section{References}

Andew. ( and Pfurluheller. (j. (194) Event-related wher-

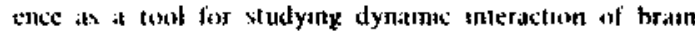

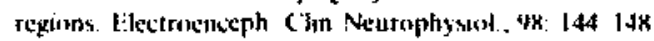

Hasitalatsun. M.C.M ina Brunia, (H. (20)1) Antfopalary

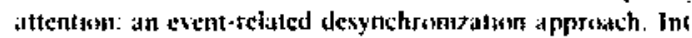
1) Prychuphysiws., 4.311. 9! 107

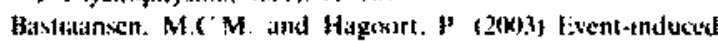
theld responses as is window on the dynarmes of memory (ortex. 39(4 5): 967 992

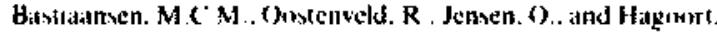

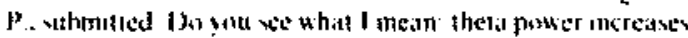

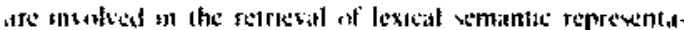
tas?

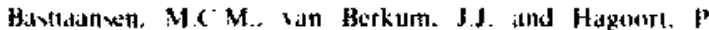
120klal Event-rolated thela power increases in the humiln EEC during onlıne sentence proxesstng. Neurosil. Lenl.. $323(1): 13 \cdot 16$.

Bavtiatnsen. M C.M. van Berkum. J.J and Hagoort. P \{30극 Syalatic procesing m(x)ulates the theta rhythm of the human EEG. Neuromine. 17,3) 1479 1497

Butstidanien. M.C.M. Van der Linden. M.. ter Keury. M. IS. jikstra. T. and Hagoort. $P$ (200)5। Thelil sesfonses ate inrolved in fexico-semantic retriesal furing lixnguage pracessing. J. Cogn. Neurovit. 1713): 5301541

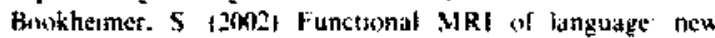
afponatches fo understanding the corlical organtzation in

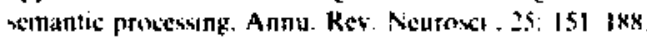

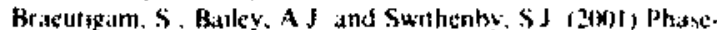

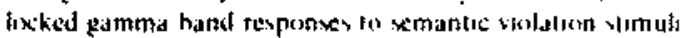

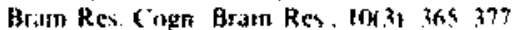

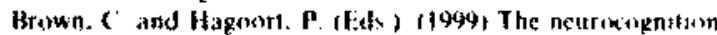

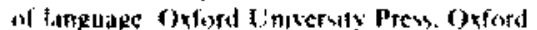

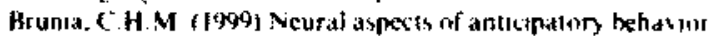
Aclid Psychotogica . 161: 213.242

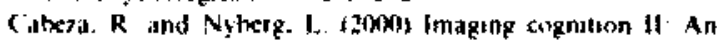
empisical revicu of 275 PET and RMRl studies I Con Neurosa. 1201: 47

Caplan. J.B. Madxen. JR, Raghavachat. S. and Kahana. M J 12001 , Distiact patterns of hran ixillations undetine tuo basic parameters of human maze karning J Veurophysint. $86 x+1.368380$ 
('vhen, t. Dehatene. $\Xi$, Naccache $L$. Lehericy, S DehiseneL.ankertz. G., Heniff. M.A. atrd Michel. F. (2000) The visual word torm area: spatial and temporal characterization of an taital slates of reading in normal sishyects and posterior splithratu patients. Brain. 1234 Pt 2k: 291 307

Eictenbaum, H. Oto. $T$ and Cohen, N.J. (1994) Two fancftonal somponents of the happociampal memory system. Behar Brain Sci. 17: $449 \cdot 517$

lichenhaum, H. Schoentaum, G., Youne, B. and Bunsey, M. If(x)h f untetonal argantzation of the happosampal memory vivem Pron Nitl Acad Sci LSA. 91 1350k 13507.

I tenk. A. Cirither, R.H. Netuper. C and Neubauer. A.C

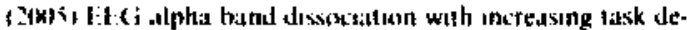

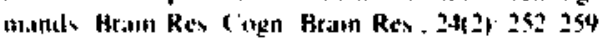

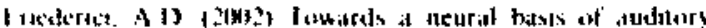

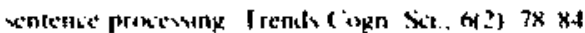

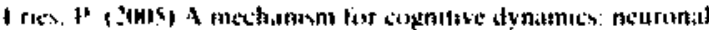

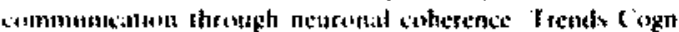

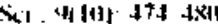

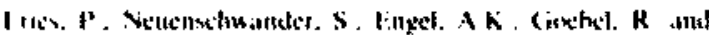

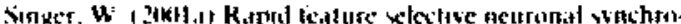

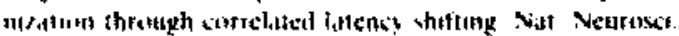

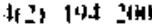

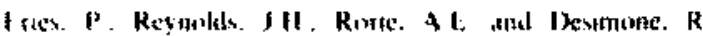

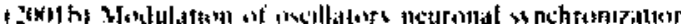

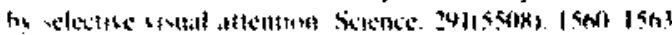

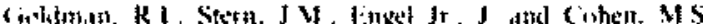

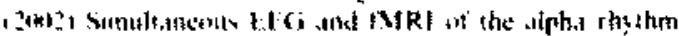

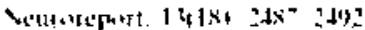

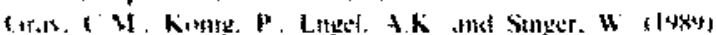

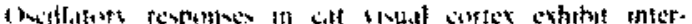

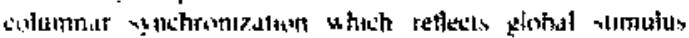
propertiss. Nature. $13 \times(62134: 33433$

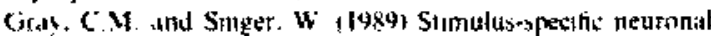

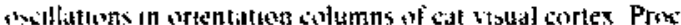

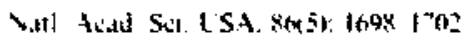

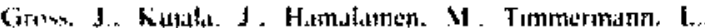

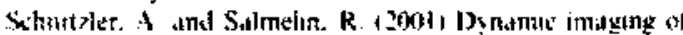

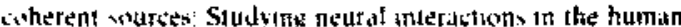

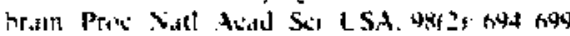

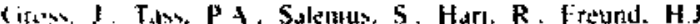

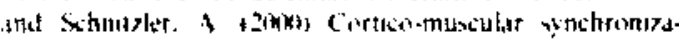

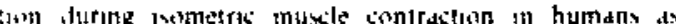

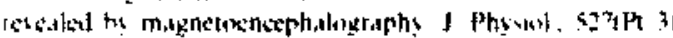
n:

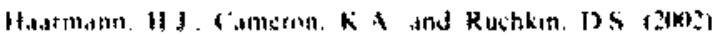

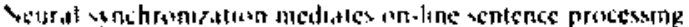

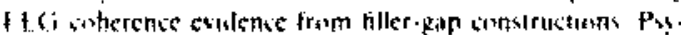

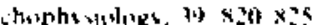

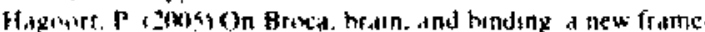

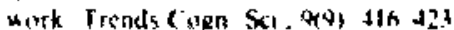

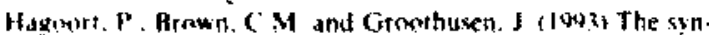
tactic poustoce shifi (SPS) as an index of wntactic prosessing l.tng Cingt Prox a 439.48?

Hagurert. P. Halic. L. Bastladnsen. M and Pecerssnn. K.M 12 mas: Integratwo of word meanung and warld knowiedge in

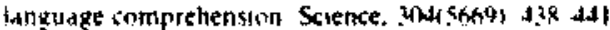

Hald. L.A., Bastiaansen, M.C. and Hagoort. P. (2006) EEG theta and gamma responses to semantic violations in online sentence processing. Brain Lang., 96(1): 90-105.

Heckers. S., Weiss, A.P.. Alpert. N.M. and Schacter, D.L. (2002) Hippocampal and brain stem activation during word retrieval after repeated and semantic encoding. Cereb. Cortex. [2(9); 900-907.

Hoogenboom. N.. Schoffelen, J.M., Oostenveld. R., Parkes. L.M. and Fries, P. (2006) Locilizing human visuat gammaband activity in frequency. time and space. Neuroimake. 29(3): 764773

inteftey, P. (2004) Hirsaktivienungen bei synliskltiches Sprachverarbeitung: eine meta-analyse. In: Müller, H.M and Ruckherl. G. (Eds.). Neurakognition Jer Spratche

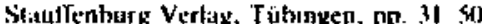

Indetfey. P. and ('utler. A (2005) Prelexical and lexical

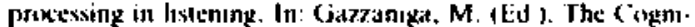
ive Neurasciencen III. MIT Press. (anbridge. MA

Indelfey. P. Kletaschenidt, A. Merholde, K.D). Kroyer, (i.

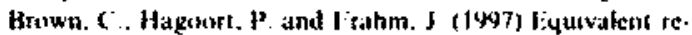

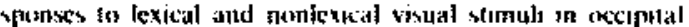
corfex it functional magnelic resinnance umaging study Ne. urommage. $5(1): 78 \mathrm{kl}$.

Kishand. M.J., Seelig. D, and Madsen, J.R. (2001) Theta returns. Curr. Opin. Neurohiol. 11(6) 739744

kiahana. M.J., Sckuler. R. Cinjan. 1.B. Kirsclen. M. and

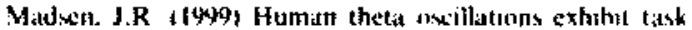
dependence slarigg vortual matre nasizatlon Nature. ?(K) $7 \times 174$.

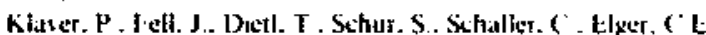
and Fernitndez. G (2(k)S, Word mitgeablity affecls the ho-

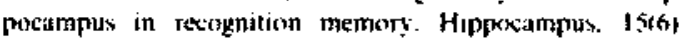
704-712.

KFimexh. W. (1999) EEG alpha and theta axcillations reflect connitise and memory porformance: a revew and dialysis Bratn Res. Rev. 29: 169. 195.

Klimesch. W., Doppelmayr, M. Pishonger. T. and Ripper. B 11407at Brain axcillatoms and human memofy. EEG corre. filtes in the upner alpha and theta bitnd. Veurosil. Lell. 230(1 2): 412

Kilmexh. W Dappeitnayr. M.. Patchonger. I. and Ruswegtet.

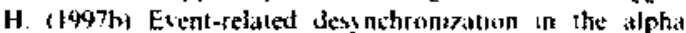
hand and the processing of semantic informalion. Bratn Rer Congh. Bratn Res, fy 21. 8394

Kilımewh. W. Rusweger. H. Donnelmavr. M and Pachenter. $T$ fivol, A melbed for the calculation af induced hand

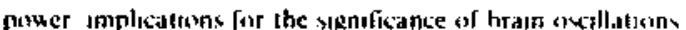
Blectivenceph Clın. Neurophystol. Ins 123 13

kionty. P and Schtllen. T.B (1941) Simułus-dependent assem. bly formation of nscillatory resnonses. I. Synchroniration Neural Comp. I 155.160

Kulas. M. and Hiłlyard. S.A. (1980) Reading senueless sen. terces. brana potentials reflect semantic incongruaty Sctence. 207: $203 \cdot 205$

Lachaux. I P. Rodraguez. E. Martinerie. J and Varela. V J (1999) Measuriag phase synchrony in bratn sgenals Hum Brain Mapp. 814) 194 208. 
Laufs. H. Klemschmuta. A. Beyerle, A.. Eger. E. SalekHaddad?. A.. Prelbtch. C. and Krikow. K. 12003\} EEGcocselated MRR of human alpha actesty. Neuroumage, $19(4)$ : 1463.1476 .

Lopes da Stlwa, F,H. (fow) Neural nleckanisms underlỵng bratn widtes from netufal membranes to networks. Electrowelkitph Cian. Nevrophystot, 79:81:93.

Mactend. C M. 144 f) Half a century of rescarch on the Stroup

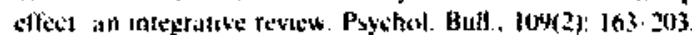

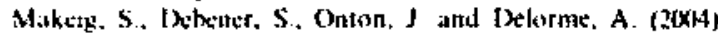
Minimg event-retated bratun dynamics. Trends Cogne. Sci. $x_{1}$ S) 2142 216

Marslet. Wilson, W atul Tyler. L.K. I I ture of vouken lingtwage understanding Cingntison. $8: 17$

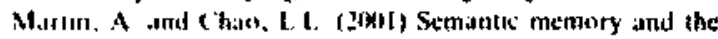

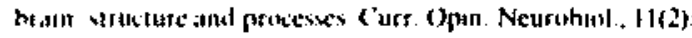
[1, : : 211

Ald ind wertal forme areal erpertise bir readiage in the funform gyrus.

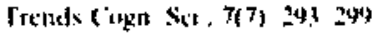

Acciuthy. G. Nobre. AC. Benten. S and Spencer, D.D.

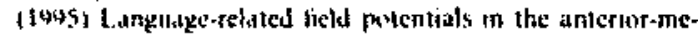
dat tempertsl isthe: I fnitractanat destrohutuon and neural genctatuss. J. Netrosco. ISI2) 1080-1089.

Mesudam. H M. (1948) From sensatton to cogntion. Brath. I26 Pt fi: 1013. 1052

Neyer. P.. Metklınger. A. Grusuat, T . Fell. J. Elger. C.E. and Fraedertit. A.D. (2005, Langudae pocessing within the humin medal temporal lobe. Hipposetmpus, $|5| 4 \mid$ : 451-459.

Miłler. R, (1991, Cortico-hipposampal interplay and the representation of contexts in the brain. Sptinger, Bertin.

Mitri. P.P. and Pesaran. B. 11999 \} Analysis of dynamic brain maging data. Biophys. J. 7e 2) 69I-708.

Murre. J.M. Grahum. K.S. and Hodges. J.R. (2001) Semantic demenus relesince to somnestionist models of tong-term memory. Bratn. 1244Pt 41: 647-675

Nobre. AC and McCarthy. G. (1995) Language-telated field putentsts in the antenor-medial temporal tobe: II Effects of werd type dat semantis pamme. J. Neutosi.. 15(2): (inn) $100 \mathrm{~s}$.

Nincz. P I . Srmwsasan. R . Wetdorp. A.F. Wyesinghe. R.S. Tuiker. D.M. Silkersteln. R.B and Codusth. PJ. (1997)

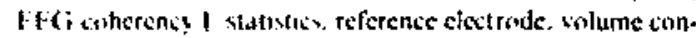

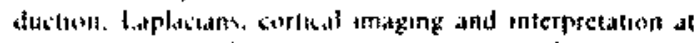

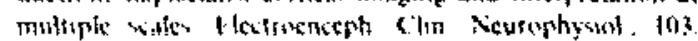
Jwh 518

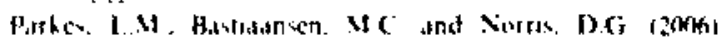

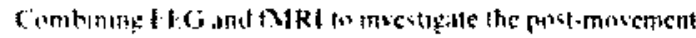

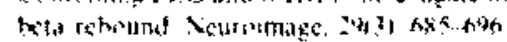

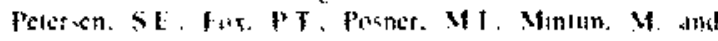

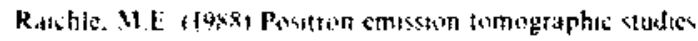
of the witical andiom! of single uord precessing Nature.

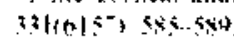

Piurtshellst. $G$ flo9:1 Exent-related synchtonization

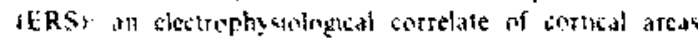

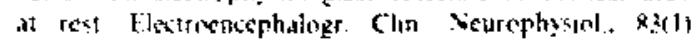
in sis
Pf̌r rscheiler, G. and Aranibar. A. (1979) Evaluation of evenirelated desynchronization (ERD) preceding and following voluntary self-paced movements. Electroencephalogr. Clin. Neurophysiol., 46: 138-146.

Pírtscheller, G. and Berghold, A. (1989) Patterns of cottical activation during planning of voluntary movement. Electroencephalogr. Clin. Neurophysiol. 72: 250-258.

Pfurtscheller, G. and Lopes da Silva, F.H. (1999;) Event. related EEG-MEG synchronization and desynchronization: Basic principles. Clin. Neurophysiol., 110: 1842- 1857.

Pfurischeller, G. and Lopes da Silva, F.H.E. 1999b. Event. related desynchronization. Handbook of Lilectroencephatogeaphy and Clineal Neurophysiology, revised serles, Vol. fo. Elsevier, Amsterdam.

Pfurtscheller. G. and Netiper. C. (1994) Event-related synchro. nization of mu rhythm in the EEG over the cortial hand area in man. Netrescici. Lett. 174(1): 93-96

Pfurlschelier, G. and Neuper. C (1997) Motor amagery acisvates pramary sensorımotor area in humans, Neuroscl. Lett. 239: 6568 .

Pfurtscheller. G.. Stancak Jr., A. and Neuper. C. (1996) Postmovement heta synchronization A correlate of an uding mo. tor area" Electroencephalogr. Clin. Neurophysiol., 98(4): 281-293

Pfurtsetheller, G., Zalaudek. K. and Neuper. C. (1998) Eventrelated beta synchronization after wrist. finger and thumb movement. Electroencephalogr. Clin. Neurophysiol.. 109. $154-160$.

Pulvernzueller, F. (1999) Words in the brain's language. Behav. Brain Sci., 22: 253-336.

Pulvernueller, F. (200I) Brain reflections of words and their meaning. Trends Cogn. Sci.. \$12): 517-524.

Pulvermueller. F.. Lutzenberger. W, and Preissl. H. (I999) Nouns and verbs in the intact brain: evidence from eventrelased potentials and high-frequency cortical responses. Cereb. Cortex. 9(5): 497-506.

Raghavachari, S., Kahana, M.J.. Rizzulo, D.S., Caplan, J.B., Kirschen, M.P., Bourgeois, B., Madsen, I.R. and Lisman. J.E, (2001) Gating of human theta oscillations by a working memory task. J. Neurosc1.. 21(9): 3175-3183.

Rizzuto. D.S., Madsen. J.R.. Bromfield. E.B.. Schulze-Bonhagc. A.. Seclig. D. Aschenbrenner-Scheibs. R. and Kahana. M.J. (2003) Reset of human neocoritcal oxilfalions during a working memory task. Proc. Natl. Acad. Soi. USA. JOYKl:3\} $7431-79,36$

Rodriguez, E.. Georze. N. Lashaux, JP. Mastinenc, J Renialt. H. and Varela. F. 1 (1999) Perception's shadow Inng-distance synchronizalinn of human bratn ackivity Nisure. 39767|8. 439 433

Rolfsema. P.R. Engel. A.K. Konte. P and Singet. W (1997) Visuomotor integration is assoxialed with zero lume. lag synchmonization among corlical areas Nature. 385 $15716 \mathrm{H}$

Rohm. D. Klimesch. W. Hakter. H and Doppeimaỵr. M 12091) The roic of theta and aipha obcillations for language comprehenson in the human electroencephalogtam. Neuknsi. Lett. 310f2 3\% 1.37 [40. 
Singer. $W$, 194:3 Synchronization of corrical aetivity and ts putatse role an information processing and learning. Ann Rer. Physitul. 55: 349-374.

Singer. W. (1999) Neuronal synckrony: a versatıle code for the delintion of relations:" Neuron. 24(I): 49-65 III-1 I-5.

Stnzer, W. and Gray. C.M. (1995) Visuat feature integration and the temporal cortetatton bypothesis. Ann. Rev. Nearoi) . Ix; $5555 \times 6$.

Sktnner, S.t. and Yingling. C.D. (1977) Central gatug mechanfoms that reztalate tyent-retated potentials and behavior

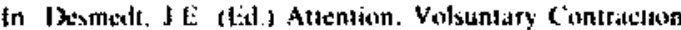

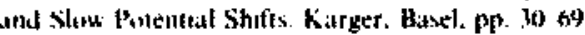

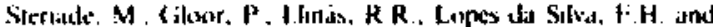

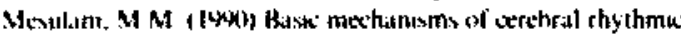

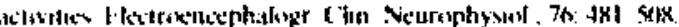

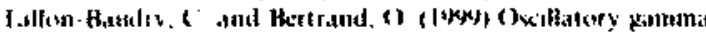

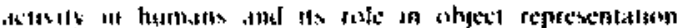

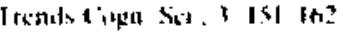

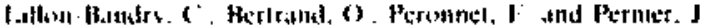

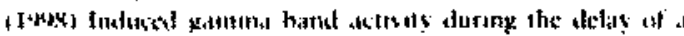

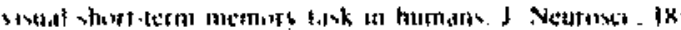
12.1 .21254

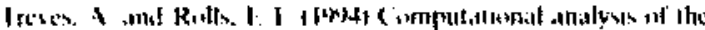

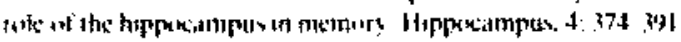

Van Berkum. J.J.. Zwitserlood. P., Bastidansen, M.. Brown, C., and Hagoort. P.. 2004. So who's "he" anyway" Differential ERP and ERSP effects of referential success. ambiguity and failure during spoken language comprehension. Paper presented at the Annual Meeling of the Cognitive Neuroscience Society. San Francisco.

Vareja. F., Lachaux, I.P., Rodriguez, E. and Martinerie. J. (2001) The brainweb: phase synchronization and large-sxale integtation. Nat. Rev. Neurosci., 2(4): 229-239.

Weiss. S. and Muelter, H.M. (2003) The contribution of EEG coherence to the investigation of language. Brain Lang. 85(2):, $325 \cdot 343$.

Weiss, S. Mueller. H.M., Schack, B. King, J.W., Kutiss. M and Rappelstoetker. P. 12005) Increased neuronal uommunıcillon accirnpisying sentence comprethenstinn. Int. J Piy. chophysicl., 57(2): 129 141

Weiss. S. Rapmelsherker, P., Schack, B. and Mueller, H M (240)? Kisharenz. und Phasenuntersuchungen und the Bedeufung fur de Untersuchung von Sprachprozesicen. In Muelker, (i.R H.M. (lid), Neutakegnttum der Sprache Stjuffentsurg. Tuhengen.

Wise. R.J (20M3) Language systems in normis and aphasce ho. mian suhjects: funcetonial imaging studies ; ind inferentes from ammil studies. Br. Med. Bult. 65: 45119 